\title{
Congenital Complete Heart Block in Fetal Echocardiography
}

\author{
Amit Kumar Singh ${ }^{1}$, Brijmohan Rajak ${ }^{2}$, Ruby Singh ${ }^{2}$, Jitendra Mandal ${ }^{3}$. \\ ${ }^{1}$ Department of Cardiology, Shahid Gangalal National Heart Centre, Janakpur Branch, Janakpurdham, Nepal. \\ ${ }^{2}$ Department of Gynecology, Provincial Hospital, State 2, Nepal. \\ ${ }^{3}$ Department of Radiology, Provincial Hospital, State 2, Nepal.
}

Corresponding Author: Amit Kumar Singh

Department of Cardiology, Shahid Gangalal National Heart Centre, Janakpur Branch, Janakpurdham.

Email: dramitsgnhc@gmail.com

Orcid ID: 0000-0003-4496-0436

Cite this article as: Singh A. K., Rajak B., Singh R., et al Congenital Complete Heart Block in Fetal Echocardiography. Nepalese Heart Journal 2021; Vol 18(2), 57-59.

Submission date: $25^{\text {th }}$ June, 2021

Accepted date: $20^{\text {th }}$ August, 2021

\begin{abstract}
Congenital Complete Heart Block (CHB) in a fetus is a rare diagnosis occurring 1 in 15,000 to 20,000 live births which can be diagnosed by echocardiography. It's less talked disease. It is uncommonly reported even in countries where fetal echocardiography is performed in much higher numbers. For countries like Nepal, where small number of fetal echocardiography is performed, we present a case of lupus as the cause of congenital CHB.
\end{abstract}

Keywords: Congenital Heart Block, lupus, Echocardiography, Hydroxychloroquine

\section{Background}

Congenital Complete Heart Block (CHB) in a fetus is a rare diagnosis occurring 1 in 15,000 to 20,000 live births ${ }^{1}$. CHB can be diagnosed by echocardiography alone $e^{2-4}$. Fetal echocardiography is a boon for fetus to get such complex diagnosis in the womb. Getting the diagnosis early is important for the prognosis of the disease is poor $^{5}$.

\section{Case Report}

A female of 27 weeks period of gestation was referred for fetal echocardiography. The anomaly scan had showed decreased fetal heart rate and renal dysplasia. The patient underwent fetal echocardiography. It showed cardiomegaly with cardiothoracic (CT) ratio $>0.6$, decreased ejection fraction to $35 \%$ by eyeballing method and heart rate of $42 \mathrm{bpm}$ with regular rhythm from the doppler signal of aortic valve (Fig. no.1)

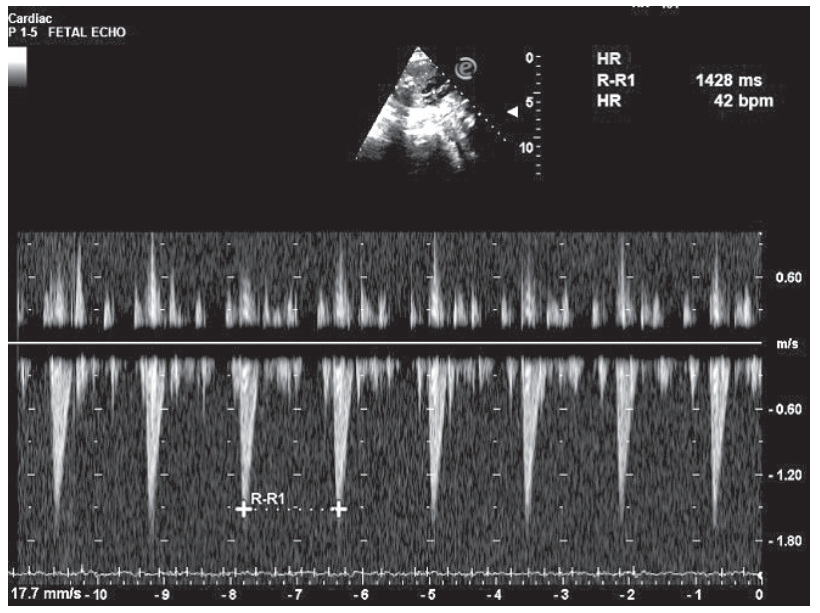

Figure 1: Doppler across aortic valve 


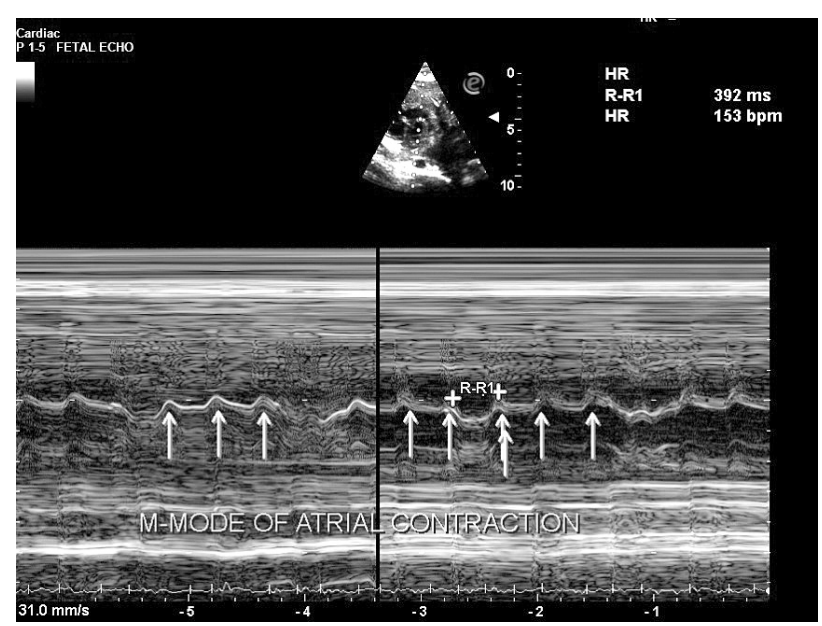

Figure 2: $M$ mode across right atrium

M-mode was performed through right atrium and atrial rate of $153 \mathrm{bpm}$ was calculated. Diagnosis of Congenital CHB was made (Fig. no. 2)

With suspicion of lupus CHB, history and examination of mother was done and her blood was sent for investigation. It showed strongly positive for Anti SSA/Ro and Anti Ro- 52 (SSA) and positive for Anti SSB/La (Table:1)

Table 1: Immunoassay Reports

\begin{tabular}{|l|l|}
\hline $\begin{array}{l}\text { Anti Nuclear Antibody } \\
\text { IgG Profile }\end{array}$ & Comments \\
\hline $\begin{array}{l}\text { Anti U1 - Sn RNP/ Sm } \\
\text { RNP }\end{array}$ & Negative \\
\hline Anti-Sm & Negative \\
\hline Anti SSA/Ro & Strongly Positive \\
\hline Anti Ro -52 (SSA) & Strongly Positive \\
\hline Anti SSB/La & Positive \\
\hline Anti Jo 1, Histidyl t-RNA & Negative \\
\hline Synthesis & Negative \\
\hline Anti CENP-B Serum & Negative \\
\hline Anti Ds DNA & Negative \\
\hline Anti Nucleosome & Negative \\
\hline Anti Histone & Negative \\
\hline Anti Rib - P - Protein & Negative \\
\hline Anti Scl - 70 & \\
\hline
\end{tabular}

Mother opted to discontinue her pregnancy for condition of the fetus explained. The risk of similar condition in next pregnancy was explained to the patient. She was advised for preconception gynaecologist consultation for next pregnancy. Repeated fetal echocardiography starting from early POG up to 28 weeks POG was advised.

\section{Discussion}

Autoimmune related Congenital Heart Block is more common than non-immune related CHB affecting 2 out 100 fetuses exposed to maternal lupus antigen ${ }^{6}$. All degrees of heart block can be diagnosed by echocardiography. M mode is taken through atria and ventricle and count the number of contractions of the two chambers. The contraction has to be regular and contraction of ventricle has to be slower than that of atrium to make the diagnosis of CHB. The other method is getting doppler signal through LVOT view to get the signal of aortic valve and mitral inflow at the same time. Doppler signal through mitral inflow having number of A wave dictates atrial rate and doppler signal through aorta denotes ventricular rate. The progression of 1st degree AV block to 3rd degree AV block can be avoided using hydroxychloroquine during pregnancy ${ }^{7-10}$. Fetal echocardiography can help getting diagnosis during early phase and can guide through treatment to avoid such situation in forthcoming pregnancies. Having a greater number of cases, a proper guideline could be developed for frequency of fetal echocardiography for such cases. This will also help in developing management guideline in autoimmune CHB in fetus. Anomaly scan should be a routine for at least one time during pregnancy. A protocol to perform fetal echocardiography once radiologists report abnormality in regular anomaly scan can be made. Fetal echocardiography should be investigation in mind of gynaecologists to find cause of recurrent abortions.

\section{Conclusion}

One of the causes of recurrent abortion is lupus congenital CHB. Early detection can avoid the progression of degree of heart block and better outcome of fetus. Fetal echocardiography should be performed more frequently to uplift the standard of care for new life before leaving mother's womb.

Disclaimers: Written consent was taken from the patient

\section{References}

1. Michaelsson M, Engle MA. Congenital complete heart block: an international study of the natural history. Cardiovasc Clin 1972;4: 85-101

2. Buyon JP, Hiebert R, Copel J, et al. Autoimmune-associated congenital heart block: demographics, mortality, morbidity and recurrence rates obtained from a national neonatal lupus registry. J Am Coll Cardiol 1998;31:1658-66. https://doi. org/10.1016/S0735-1097(98)00161-2

3. Eronen M, Siren MK, Ekblad H, Tikanoja T, Julkunen H, Paavilainen T. Short and long-term outcome of children with congenital complete heart block diagnosed in utero or as a newborn. Pediatrics 2000;106:86-91. https://doi.org/10.1542/ peds.106.1.86

4. Groves AMM, Allan LD, Rosenthal E. Outcome of isolated congenital complete heart block diagnosed in utero. Heart 1996;75:190-4. https://doi.org/10.1136/hrt.75.2.190

5. Jaeggi ET, Hamilton RM, Silverman ED, Zamora SA, Hornberger LK. Outcome of children with fetal, neonatal or childhood diagnosis of isolated congenital atrioventricular block. J Am Coll Cardiol 2002;39:130-7. https://doi. org/10.1016/S0735-1097(01)01697-7

6. Brucato A, Frassi M, Franceschini F et al. Risk of congenital complete heart block in newborns of mothers with anti-Ro/ SSA antibodies detected by counterimmunoelectrophoresis: a prospective study of 100 women. Arthritis Rheum 2001;44:18325. https://doi.org/10.1002/15290131(200108)44:8<1832::AID-ART320>3.0.CO;2-C 
7. Tunks RD, Clowse MEB, Miller SG, Brancazio LR, Barker PCA. Maternal autoantibody levels in congenital heart block and potential prophylaxis with antiinflammatory agents. Am J Obstet Gynecol 2013;208:64.e17. https://doi.org/10.1016/j. ajog.2012.09.020

8. Zmirly PM, Costedoat-Chalumeau N, Pisoni CN et al. Maternal use of hydroxychloroquine is associated with a reduced risk of recurrent anti-SSA/Ro associated cardiac manifestations of neonatal lupus. Circulation 2012;126:7682. https://doi.org/10.1161/CIRCULATIONAHA.111.089268

9. Zmirly PM, Costedoat-Chalumeau N, Saxena A et al. First stage of a Simon's two-stage optimal approach supports placental transfer of hydroxychloroquine and a reduced recurrence rate of the cardiac manifestations of neonatal lupus (abstract). Arthritis Rheum 2013;65: S1212.

10. Saxena A, Izmirly PM, Han SW et al. Serum biomarkers of inflammation, fibrosis, and cardiac function in facilitating diagnosis, prognosis, and treatment of anti-SSA/Ro associated cardiac neonatal lupus. J Am Coll Cardiol 2015; 66:9309. https://doi.org/10.1016/j.jacc.2015.06.1088 